\title{
Analytical successional tools of fouling communities submitted to different light effects
}

\author{
B. P. Masi ${ }^{1,2}$, R. Coutinho ${ }^{1,2}$ and I. R. Zalmon ${ }^{2,3}$ \\ ${ }^{1}$ Instituto de Estudos do Mar Almirante Paulo Moreira IEAPM, Divisão de Biotecnologia Marinha, Rua Kioto 253, \\ 28930-000, Arraial do Cabo, RJ, Brasil \\ ${ }^{2}$ Laboratório de Ciências Ambientais, Centro de Biociências e Biotecnologia, Universidade Estadual do Norte \\ Fluminense, Av. Alberto Lamego 2000, 28013-602, Campos dos Goytacazes, RJ, Brasil \\ ${ }^{3}$ Corresponding author. Email: ilana@uenf.br
}

Keywords: Biofouling, Colonization, Modeling, Transition probability.

\begin{abstract}
The present study uses transition matrices to compare successional processes (colonization, disturbance, persistence and replacement) of fouling communities submitted to different light effects on Cabo Frio Island, a seasonal upwelling region. Twelve functional groups were identified, and differences in the transition probabilities shown by the matrices suggest a preference for the replacement property of functional groups, which indicates the facilitation successional mechanism. The probability of colonization of these groups differed according to the direction of the substrate, which caused a negative effect of light reduction on algae with a greater probability of disturbance (sensu species replacement), which is typical of a more stressful environment. Species of the same functional group replace each other through competition and herbivory, which promotes the distinction between earlier and later groups on the successional process. Successional trajectories evaluated through global transition matrices change at each time step because they depend on the species turnover rate, and therefore, they are informative of the changing processes of the community. The probabilistic rate of changes related to successional processes may be used to evaluate future conditions of fouling communities, and the deterministic components and stochastic elements will render these communities self-organizable.
\end{abstract}

\section{Introduction}

Ecological succession is the sequential replacement of organisms over time (Clements 1916), and it is a concept particularly appropriate for answering questions of biodiversity loss, climate change, invasive species and ecological restoration (Prach and Walker 2011). Studies on succession usually emphasize analytical methods, including ecological indices (e.g., diversity) and multivariate methods (e.g., grouping, ordering). Although regarded as classic methods they should not be considered complete. A complementary approach, according to Giordano (2001), seeks to highlight species replacement patterns based on the probability of change, and transition probability matrices for species and guilds can be used to improve analyses of successional processes (Tanner et al. 1994).

A transition matrix summarizes all of the data related to the replacement of one organism for another to yield a set of probabilistic rules that establish the possible patterns of ecological succession from any possible point of departure (Gotelli 2009). Thus, it describes the ecological processes of the community in terms of disturbance, replacement and persistence, which determine the succession (Hill et al. 2004).

The early life stages of many benthic organisms are pelagic and dispersed across oceans. The set of processes by which an organism occupies a particular area includes disper- sion, settlement and recruitment and is termed colonization. The attachment process of these organisms includes settlement and encompasses two phases: the searching behavior for the attachment site and the permanent attachment to the substrate, a process that involves metamorphosis (López and Coutinho 2008). Individuals that have survived up to a specific size after settlement without reaching adulthood enter benthic communities through recruitment. The transition from vacant substrate occurs through recruitment or the vegetative growth of proximal organisms (Greene et al. 1983, Sebens 1986).

Connell and Slatyer (1977) suggested three mechanisms whereby one species might affect the establishment of another. Pioneer species may prepare the substrate for colonization by another species, share the habitat or inhibit the growth of other organisms. Subsequent studies have indicated that the proposed mechanisms occur, sometimes concurrently, in different communities (Dean and Hurd 1980, Breitburg 1985). Successional sequence in the marine environment is complex and dynamic and there are still many points to be cleared up.

Most of the models that address inter-specific interactions are not effective in complex systems with large numbers of species, which complicates assessments of the effect of different types of disturbances. Markovian models have been successfully used in community ecology in different sessile communities in terrestrial and marine environments to illus- 
trate the different successional processes of the community, including colonization, disturbance, resistance and resilience (Usher 1979, Tanner et al. 1994, Giordano 2001, Wootton 2001, Hill et al. 2004, Sauer-Machado 2006, Pawlowski and McCord 2009).

Markovian models follow the path of taxonomic or functional groups over time and are based on the assumption that the organism at some future time point $t+1$ will exclusively depend on its condition at the present time $t$ (Tanner et al. 1994). Therefore, this approach based on transition matrices and sensitivity analyses manages to predict the replacement of species or functional groups over time.

Disturbances often play a central role in the dynamics of benthic communities by creating a patch mosaic at different successional stages (Underwood 1999). Fouling assemblage under high light intensity show a greater probability of disturbance (sensu species replacement), since this physical variable is considered as a disturbing effect to several fouling larvae during the settlement phase (Svane and Young 1989, Glasby 1999, 2000, Maughan 2001). Considering disturbances as non-catastrophic discrete events that may or not damage or kill all organisms, a wide range of changes in the relationships between species will result (Platt and Connell 2003). The prediction model based on the transition probability matrix of a biological community is open and allows new species to emerge over time. Thus, it may include large disturbances that remove species because new recruitments are feasible.
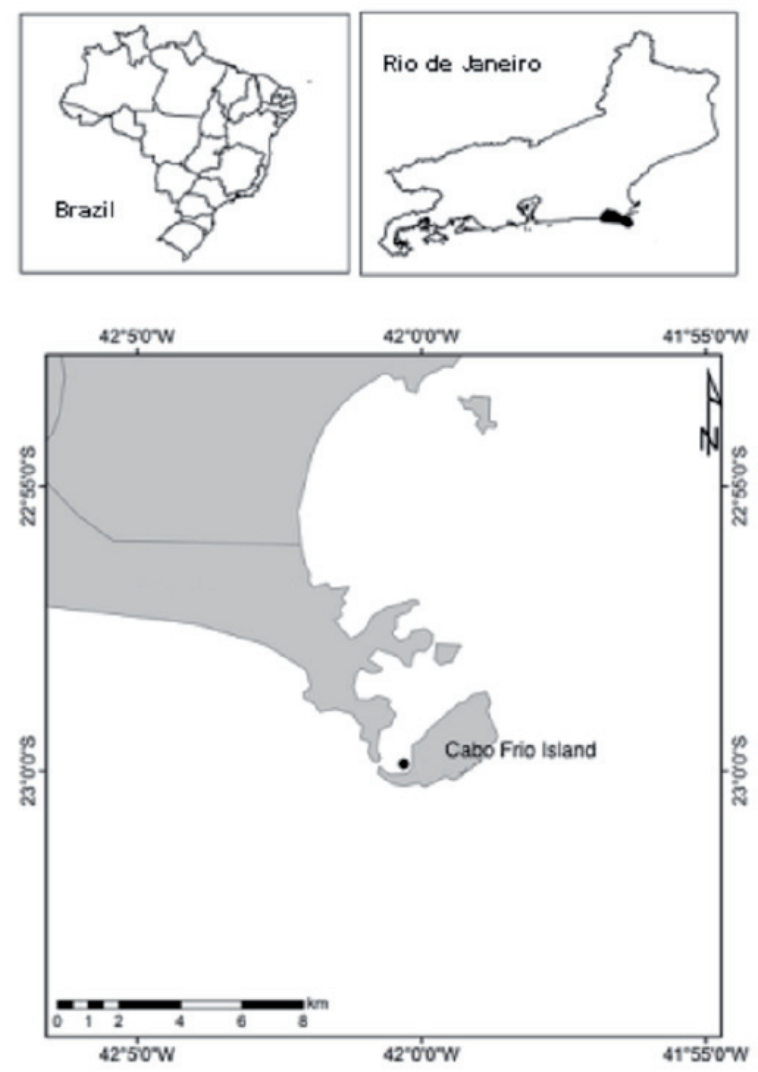

Figure 1. Location of the study site $(\bullet)$ on Cabo Frio Island, Rio de Janeiro State, southeastern Brazil.
In general, successional studies on marine ecosystem focus mainly on biological interactions and physical variables or larvae supply and colonization to understand the emerging patterns. Here we will show that changes in the community composition can be projected in a future time.

The present study use transition matrices in a fouling community to evaluate the possibility of inference on probabilistic rules (colonization, disturbance, persistence and replacement) when submitted to different light effects, since different degrees of shading could explain the different coverage of many growing epibiota (Glasby 1999). The following issues were raised: 1 . Are there preferential transitions for certain functional groups in the community? What is the complexity of the species replacement? 2. Is the fouling community succession a sequence of independent or cascading stages?

This study hypothesizes that fouling community composition under different light effects will generate different probabilistic rates, and results in divergent successional processes.

This is an ecological application research, which uses fouling community as a model to predict the future paths on the community successional processes. There are very few studies with this approach and it is a very promising tool in other ecological fields, either marine or terrestrial ecosystem.

\section{Materials and methods}

Study area. The study was conducted on Cabo Frio Island (2300'04.46” S, 4200'20.19” W), southeastern Brazil (Figure 1), in a small sandy cove surrounded by rocky shores, where upwelling events are frequent. Valentin et al. (1987) demonstrated the significant influence of local winds on fluctuations in the thermocline. Discrete upwelling events may occur throughout the year but are more intense and frequent during the spring-summer months (Guimaraens et al. 2005). Sedimentation rates in the Cabo Frio upwelling zone range from $0.26 \mathrm{~mm}$.year ${ }^{-1}$ to $0.66 \mathrm{~mm}$.year ${ }^{-1}$ (Mahiques et al. 2005).

\section{Experimental design}

Five multi-experiment units were affixed to the substrate, and they individually supported three experimental PVC panels $(20 \mathrm{~cm} \times 15 \mathrm{~cm})$ arranged horizontally at approximately $3.5 \mathrm{~m}$ deep (Figure 2). Each structure was composed of a PVC tube (5 m high and $20 \mathrm{~cm}$ diameter) supported on a cement block weighing approximately $350 \mathrm{~kg}$. The multi-experiment units were placed at a distance of $10 \mathrm{~m}$ from each other and parallel to the beach line.

The light reduction effect was evaluated according to Masi (2012), in which the associations were compared between the upper and lower sides of the experimental panels, with significant differences over the respective successional paths (upper side: $792.9 \pm 52.5 \mu \mathrm{mol} \mathrm{s}^{-1} \mathrm{~m}^{-2}$; lower side: $\left.156.5 \pm 11.2 \mu \mathrm{mol} \mathrm{s}^{-1} \mathrm{~m}^{-2} ; \mathrm{p}=0.00\right)$. 


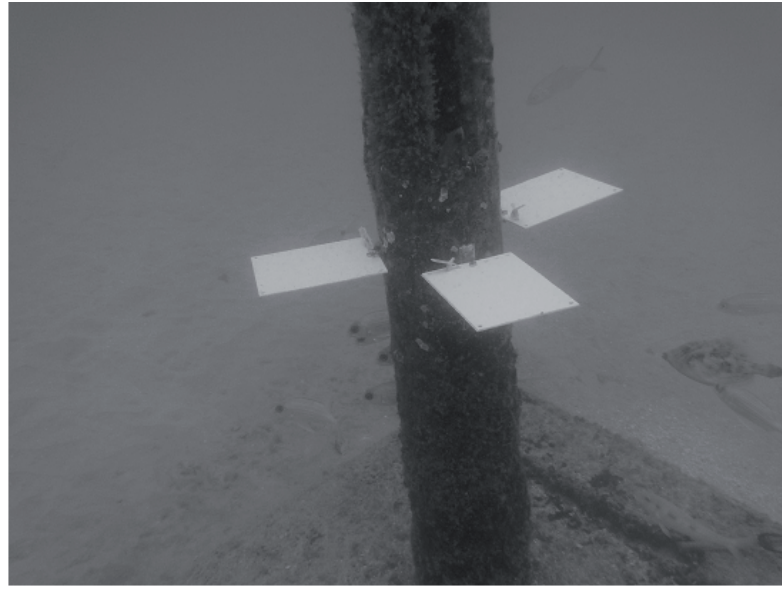

Figure 2. Biofouling multi-experimental units used to support the PVC panels.

Five panels with one from each multi-experimental unit were sampled monthly for 12 months. Each side of the five sampled panels provided 100 points of contact at each sampling interval, for a total of 6000 points on the upper and 6000 on the bottom side (12 times). Each replicate ( $N_{\text {total }}=5$ panels/ month) provided 11 transitional matrices $\left(N_{\text {total }}=55\right.$ matrices $)$ for 12 months.

\section{Fouling community}

The initial immersion of the panels occurred on July 2009 (T0), and sampling of the fouling community was conducted monthly from August 2009 (T1) to July 2010 (T12) after 12 months of immersion. Encrusting associations were sampled by divers through "in situ" photographs, which avoided possible interference from handling the experimental panels and supplied a permanent record of the data. A DC1200 SeaLife 12-megapixel digital camera was used in macro mode, which is designed to focus at short and fixed distances.

The identification of each functional group in each panel was performed using the method of contact points, wherein a 100 -point grid ( 10 rows and 10 columns) was designed with a border of identical shape and size in the software Coral Point Count with Microsoft Excel extensions (Kohler and Gill 2006); this method was able to estimate the points at the same exact site over the 12 monthly periods of immersion. The point contact design corresponds to approximately a $2-\mathrm{cm}$ interval on the actual substrate, which approximates the size of the smallest organisms in the data set.

The analysis of sessile community patterns via groupings based on functional aspects of their morphology and anatomy provides substantial insight into community structure since the limiting space is common and the abundances reflect their competitive ability. According to Steneck and Dethier (1994) and Phillips et al. (1997), a functional group analysis can be applied more broadly than is possible at the level of species or among related higher taxa. Sorting out species-level "noise" from significant changes in community structure is a goal of the functional approach that often corresponds to ecological characteristics.

The taxonomic nomenclature followed the Integrated Taxonomic Information System (ITIS 2009). Discrete functional or taxonomic groups were defined based on Steneck and Dethier (1994) and De Messano et al. (2009): biofilm 1, biofilm 2, articulate calcareous algae, encrusting algae, macrophyta corticate, filamentous algae, sponge, Hydrozoa, Cirripedia and encrusting bryozoans (Table 1). Biofilms 1 and 2 were differentiated through the identification of the main biofilm-forming organisms (Table 1). A functional group thus comprises the intrinsic characteristics (e.g., morphological and anatomical) that contribute to its ecological success at some point along the continua of potential disturbances. The time unit of the model was 30 days, although an error of five days was considered because of the weather conditions that precluded access to the study site at exactly 30 -day intervals.

\section{Data analysis}

The construction of the transition matrix was conducted according to Giordano (2001) and the assumptions of the matrix model of succession according to Gotelli (2009). The number of contacts at each panel directly represented the percentage cover of functional groups. Square matrices were created from the original matrix of the record of contacts, and the successive functional groups were included over time. These matrices showed the transitions of the functional groups in absolute values, with the groups that were replaced (FROM) in columns and the groups that replaced them (TO) in rows; thus, the matrices showed the probability of different transitions between the groups. The matrices were prepared for each panel and month and for the total set of panels and months. The sum of the values of each column represents all of the transitions $(100 \%)$ at all of the points on the set of plates, and the sum of rows showed the ability of each functional group to displace the others and cover the previously occupied space. A matrix of the probabilities of the different transitions between groups was generated from the absolute values of the data from each matrix by dividing these values by the total number of contact points analyzed in each panel. According to the assumptions of the succession model (Gotelli 2009), the transition probabilities do not depend on the spatial arrangement of patches (our functional groups). In other words, the probability of change does not depend on the identity of neighboring groups.

Two ratios were added to express the additive relationship established between the loss and gain of functional groups as components of turnover: the first one between the number of lost groups and the groups present at the starting time and the second ratio was between the number of gained groups and the groups present at a subsequent time. The functional group "empty space" was included because it is a limiting resource for the fouling community. To complement the turnover index value, it was assigned a negative sign when the relative loss outweighs the relative gain. The turnover index was based on Giordano (2001): $T=L / S T_{n}+G / S T_{n+1}$, where $L$ is the number of functional groups present at time $T_{n}$ and absent at 
time $T_{n+1}$ (lost groups), $G$ is the number of functional groups absent at time $T_{n}$ and present at time $T_{n+1}$ (gained groups), $S T_{n}$ $=$ the number of groups, and $S T_{n+1}=$ the number of groups at time $T_{n+1}$.

The means and confidence interval limits $(N=5$ panels/month/side) were assessed using the bootstrap method (Caswell 2001). $N$ sets of size $\mathrm{n}$ were drawn from the $\mathrm{n}$ sample values, and the respective bootstrap mean for each one was calculated. These $N$ means were ordered in increasing sequence to obtain the values corresponding to percentiles $\alpha / 2$ and $1-\alpha / 2$, which represent the lower and upper limits of the confidence interval, respectively. We used $N=10,000$, considering $\alpha=0.05$ for $n=5$.

The coefficient of complexity was calculated for each panel at each time point and it related the number of effective transitions of functional groups (number of groups recorded in each time point) to the total number of possible transitions (total number of functional groups recorded throughout the study). A higher coefficient value indicated a greater number of functional groups replaced at a specific time point and, therefore, an increased complexity of the web (Giordano 2001). The means and confidence interval limits ( $N=5 / \mathrm{month} / \mathrm{side})$ at each panel orientation were also assessed using the aforementioned bootstrap method.

The transition probability matrix from time $t$ to the next time $t+1$ was created from the absolute data of each functional group at each time divided by the total number of contact points. The transition probabilities were evaluated according to Hill et al. (2004) and were based on four successional processes of the organisms in the community development: colonization, disturbance, persistence and replacement. Colonization is thought to occur when a group occupies a point that was previously vacant. Persistence occurs when a point occupied by a group at time $t$ remains occupied by the same group at time $t+1$. Replacement occurs when a point occupied by a group at time $t$ is replaced by another group at time $t+1$. Disturbance occurs when a point occupied by a group at time $t$ becomes vacant at $t+1$.

\section{Results}

A total of 10 functional groups were identified (Table 1). The filamentous algae group was the most common and abundant on both faces of the panels, and it was followed by Cirripedia on the upper face and Hydrozoa on the lower ones (Table 1).

The mean values of the turnover rate over the 12 months indicated a decreasing trend on both sides of the panels, with a higher gain of functional groups in the first half of the study period (Figure 3). The negative values indicated that the loss of functional groups exceeded the relative gain on the lower side of the panels at months 3 and on both sides at month 11 (Fig. 3a, b)

The coefficient of complexity for the set of transitions was higher on the upper face of the panels throughout the entire period except for month 10; a downward trend began from this stage, indicating a less complex web of transitions on the
Table 1. Functional groups recorded on the experimental panels at Cabo Frio Island from July 2009 to July 2010, and the number of points in each face of the panels. Functional groups are indicated in the text by the code recorded in the second column of the Table.

\begin{tabular}{lccc}
\hline \multicolumn{1}{c}{ Functional group } & Code & $\begin{array}{c}\text { Up } \\
\text { face }\end{array}$ & $\begin{array}{c}\text { Low } \\
\text { face }\end{array}$ \\
\hline $\begin{array}{l}\text { Biofilm 1 (diatoms including } \\
\text { Nitzschia, microalgae and } \\
\text { bacteria) }\end{array}$ & BI & 306 & 443 \\
$\begin{array}{l}\text { Biofilm 2 (diatoms exclud- } \\
\text { ing Nitzschia, microalgae and } \\
\text { bacteria) }\end{array}$ & MI & 323 & 50 \\
Articulate calcareous algae & CA & 626 & 0 \\
Crustose algae & CR & 18 & 176 \\
Filamentous algae & FI & 2182 & 1968 \\
Macrophyta corticate & MC & 0 & 4 \\
Encrusting bryozoan & BC & 25 & 658 \\
Cirripedia & CI & 1036 & 437 \\
Sponge & ES & 183 & 204 \\
Hydrozoa & HI & 667 & 1621 \\
\hline Bare space & 634 & 439 \\
\hline Total & & 6000 & 6000 \\
\hline
\end{tabular}

community than at the earlier successional process (Figure 4). The complexity of replacement within the functional groups remained stable on the lower side, with the highest peak at month 10; subsequently, the number of effective transitions decreased, which was similar to the upper side.

The successional transition probabilities of the functional groups could be assessed from the global matrices for all of the observation times at each side of the panels (Tables 2-3). At the lower side, the bare space at the beginning of the succession was mainly occupied by the biofilm 1 group (7.2\%), replaced by filamentous algae $(5.7 \%)$ and then preferably occupied by Hydrozoa (7.4\%; Table 2). At the upper side, the initially bare space was mainly occupied by the filamentous algae group $(8.1 \%)$ and replaced by Cirripedia $(3.9 \%)$ and then by Hydrozoa ( $2.9 \%$; Table 3$)$. For both sides, these groups were the most persistent and preferentially replaced by each other (Tables 2, 3).

A total of four types of transitions occurred: a) from a bare space to any functional group (colonization); b) from a functional group to a bare space (disturbance); c) from one specific group to another (replacement); and d) from one group to the same group (persistence).

The transition probabilities considering the successional process of colonization of the functional groups showed that the main earlier colonizers were filamentous algae on the upper face of the panels (8.1\%) and biofilm 1 on the lower one (7.2\%; Figure 5a). Apart from these, only Hydrozoa showed 
Table 2. Global transition matrix of the functional groups on the low face of the panels with the replaced groups (FROM) in the columns and groups that replaced them (TO) in the rows. Mean values of 60 matrices corresponding to the observation times with 6000 points of contact on five panels sampled monthly of the fouling community on Cabo Frio Island. The functional group codes are listed in Table 1.

\begin{tabular}{|c|c|c|c|c|c|c|c|c|c|c|c|}
\hline & BI & MI & FI & $\mathrm{CA}$ & $\mathrm{CR}$ & CI & HI & $\mathrm{BC}$ & ES & $\mathrm{MC}$ & VA \\
\hline BI & 0.0017 & 0.0000 & 0.0007 & 0.0000 & 0.0000 & 0.0000 & 0.0003 & 0.0000 & 0.0000 & 0.0000 & 0.0720 \\
\hline MI & 0.0043 & 0.0010 & 0.0032 & 0.0000 & 0.0000 & 0.0000 & 0.0000 & 0.0000 & 0.0000 & 0.0000 & 0.0002 \\
\hline FI & 0.0568 & 0.0055 & 0.1745 & 0.0000 & 0.0033 & 0.0092 & 0.0388 & 0.0028 & 0.0008 & 0.0003 & 0.0355 \\
\hline $\mathrm{CA}$ & 0.0000 & 0.0000 & 0.0000 & 0.0000 & 0.0000 & 0.0000 & 0.0000 & 0.0000 & 0.0000 & 0.0000 & 0.0000 \\
\hline $\mathrm{CR}$ & 0.0002 & 0.0003 & 0.0058 & 0.0000 & 0.0073 & 0.0010 & 0.0102 & 0.0017 & 0.0002 & 0.0000 & 0.0027 \\
\hline CI & 0.0020 & 0.0002 & 0.0252 & 0.0000 & 0.0005 & 0.0232 & 0.0168 & 0.0017 & 0.0010 & 0.0000 & 0.0023 \\
\hline HI & 0.0002 & 0.0008 & 0.0740 & 0.0000 & 0.0092 & 0.0287 & 0.1360 & 0.0100 & 0.0137 & 0.0000 & 0.0120 \\
\hline $\mathrm{BC}$ & 0.0002 & 0.0000 & 0.0117 & 0.0000 & 0.0038 & 0.0032 & 0.0222 & 0.0613 & 0.0023 & 0.0000 & 0.0050 \\
\hline ES & 0.0000 & 0.0000 & 0.0043 & 0.0000 & 0.0025 & 0.0033 & 0.0108 & 0.0013 & 0.0108 & 0.0000 & 0.0008 \\
\hline $\mathrm{MC}$ & 0.0000 & 0.0000 & 0.0000 & 0.0000 & 0.0000 & 0.0000 & 0.0003 & 0.0000 & 0.0000 & 0.0003 & 0.0000 \\
\hline VA & 0.0083 & 0.0005 & 0.0258 & 0.0000 & 0.0015 & 0.0020 & 0.0071 & 0.0020 & 0.0007 & 0.0000 & 0.0102 \\
\hline
\end{tabular}

(a)

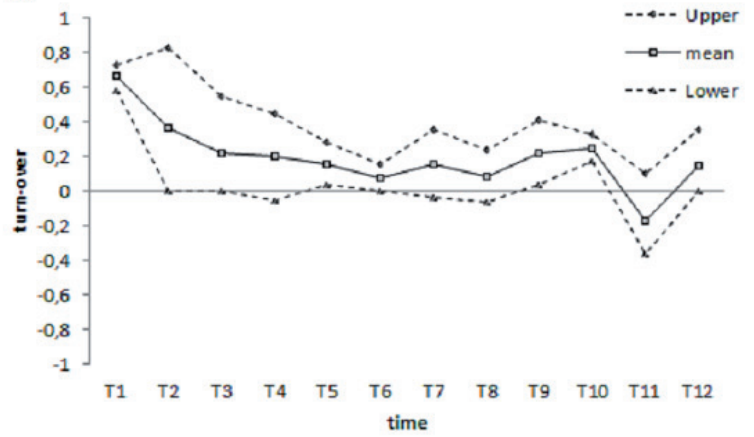

(b)

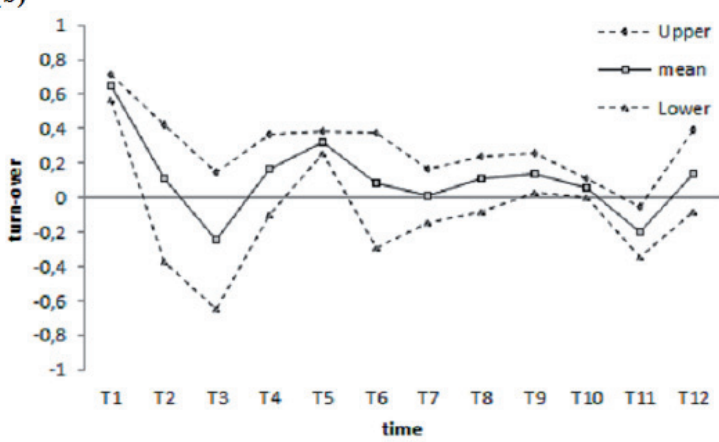

Figure 3. Bootstrap mean of the turnover index in the upper (a) and bottom (b) faces of the experimental panels over the 12-month immersion period on Cabo Frio Island, Rio de Janeiro ( $N=5$ panels/month/face). The upper and lower limits refer to the confidence intervals $(\alpha=0.05)$ estimated by bootstrap analysis.

(a)

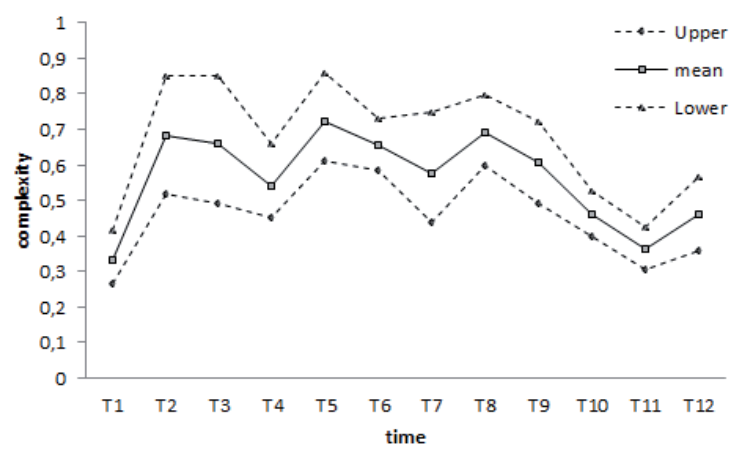

(b)

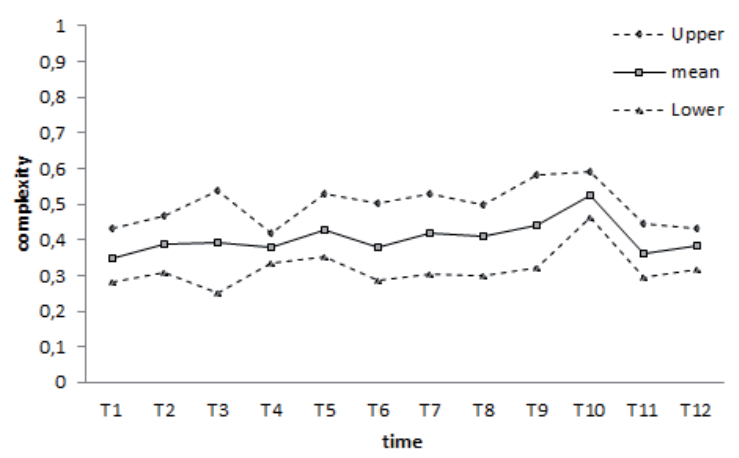

Figure 4. Bootstrap mean of the complexity index related to the transitions of functional groups on the upper (a) and bottom (b) faces of the experimental panels over the 12-month immersion period on Cabo Frio Island, Rio de Janeiro ( $N=5$ panels $/$ month/face). The upper and lower limits refer to the confidence intervals $(\alpha=0.05)$ estimated by bootstrap analysis. 
Table 3. Global transition matrix of the functional groups on the up face of the panels, with the replaced groups (FROM) in the columns and groups that replaced them (TO) in the rows. Mean values of 60 matrices corresponding to the observation times with 6000 points of contact in five panels sampled monthly of the fouling community on Cabo Frio Island. The functional group codes are listed in Table 1.

\begin{tabular}{lcccccccccc}
\hline & BI & MI & FI & CA & CR & CI & HI & BC & ES & VA \\
\hline BI & 0.0048 & 0.0000 & 0.0042 & 0.0000 & 0.0000 & 0.0002 & 0.0000 & 0.0000 & 0.0000 & 0.0418 \\
MI & 0.0005 & 0.0147 & 0.0243 & 0.0000 & 0.0000 & 0.0047 & 0.0008 & 0.0000 & 0.0000 & 0.0088 \\
FI & 0.0348 & 0.0000 & 0.1975 & 0.0015 & 0.0000 & 0.0168 & 0.0100 & 0.0002 & 0.0000 & 0.0810 \\
CA & 0.0000 & 0.0010 & 0.0072 & 0.0473 & 0.0015 & 0.0190 & 0.0153 & 0.0000 & 0.0058 & 0.0072 \\
CR & 0.0000 & 0.0000 & 0.0000 & 0.0008 & 0.0002 & 0.0008 & 0.0008 & 0.0000 & 0.0000 & 0.0003 \\
CI & 0.0037 & 0.0060 & 0.0385 & 0.0082 & 0.0000 & 0.0872 & 0.0183 & 0.0003 & 0.0013 & 0.0092 \\
HI & 0.0002 & 0.0263 & 0.0292 & 0.0067 & 0.0002 & 0.0212 & 0.0375 & 0.0005 & 0.0023 & 0.0090 \\
BC & 0.0000 & 0.0000 & 0.0000 & 0.0003 & 0.0000 & 0.0005 & 0.0022 & 0.0003 & 0.0002 & 0.0007 \\
ES & 0.0000 & 0.0003 & 0.0027 & 0.0067 & 0.0007 & 0.0027 & 0.0057 & 0.0002 & 0.0093 & 0.0023 \\
VA & 0.0070 & 0.0055 & 0.0498 & 0.0037 & 0.0005 & 0.0080 & 0.0070 & 0.0000 & 0.0012 & 0.0230 \\
\hline
\end{tabular}
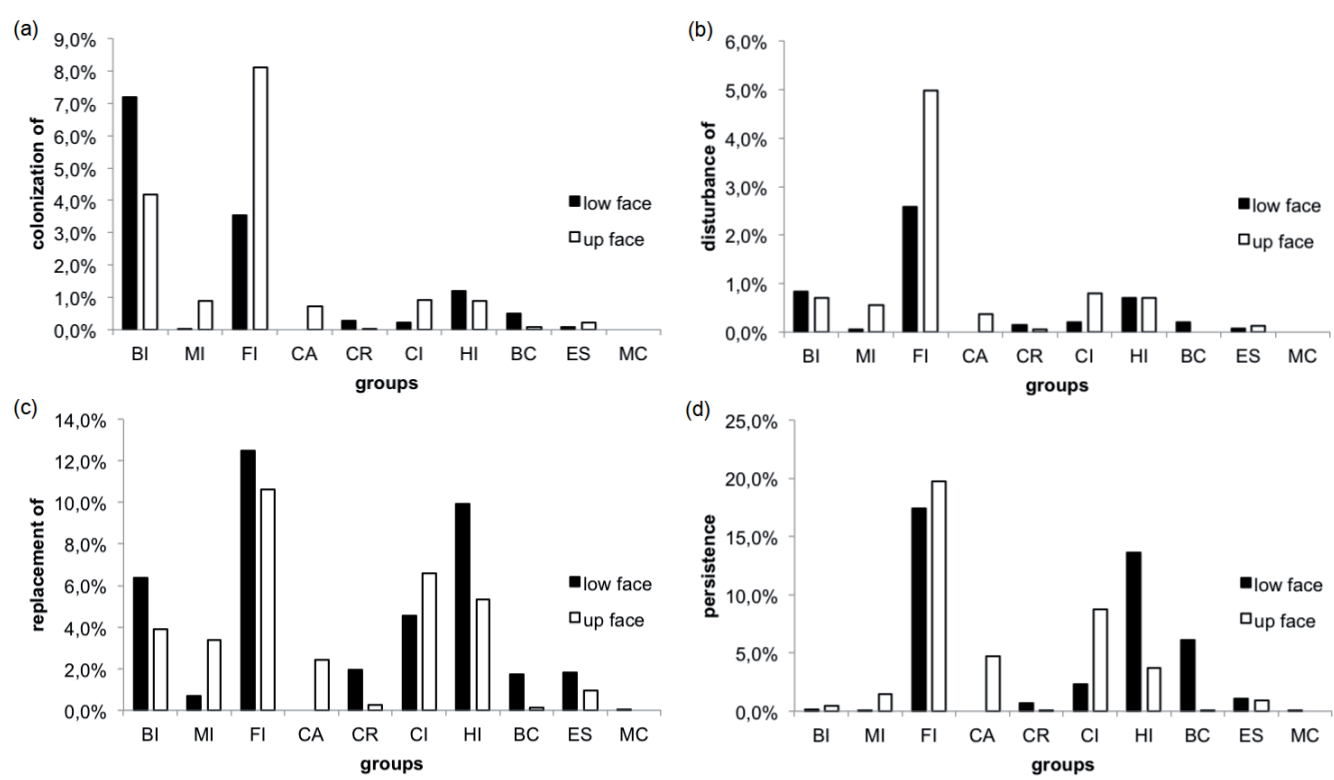

Figure 5. Transition probabilities on the up and low faces of the experimental panels over time on Cabo Frio Island, Rio de Janeiro ( $N$ $=5$ panels/month/face): $\mathbf{a}$. FROM bare space TO any functional group (colonization), b. FROM any functional group TO bare space (disturbance), c. FROM any functional group TO another group (replacement), d. FROM one group TO the same group (persistence). The functional group codes are listed in Table 1.

a probability of colonizing higher than $1 \%$ on both faces. The sum of the transition probabilities showed that the upper face of the panels (18.3\%) was more likely to colonize by the functional groups than the lower ones $(7.1 \%)$.

The probability of transition from any functional group to bare space, which indicates disturbance, was greater for filamentous algae on the upper and lower faces of the panels, which showed values of 5.0 and $2.6 \%$, respectively (Figure $5 \mathrm{~b})$. The other groups showed a probability of substrate vacancy lower than $1 \%$. Biofilm 2, articulate calcareous algae and Cirripedia showed the greatest probability of disturbance on the upper faces, and biofilm 1, encrusting algae and
Hydrozoa had the highest probability of disturbance on the lower ones. The sum of the transition probabilities showed that the upper face features a likelihood of disturbance approximately twice that of $(10.57 \%)$ the lower face $(5.81 \%)$.

The probability of transition from a specific group to another, which indicates replacement, was higher in the lower side of the panels and was represented by filamentous algae (12.4\%), Hydrozoa (9.9\%) and Biofilm 1 (6.2\%) (Fig. 5c). On the upper side, the main substitutions occurred from filamentous algae (10.7\%), Cirripedia (6.6\%) and Hydrozoa (5.7\%) to another functional group (Fig. 5c). The sum of transition probabilities showed that the lower side (38.1\%) had a higher 
probability of substitution of functional groups than the upper side $(33.7 \%)$.

The probability of a group remaining in the fouling community differed between the panel sides, especially for the groups Cirripedia, Hydrozoa and encrusting bryozoans (Figure 5d). Cirripedia was more persistent on the upper side (8.9\%), whereas Hydrozoa and encrusting bryozoans were more persistent on the lower one at 13.6 and $6.7 \%$, respectively. The persistence of filamentous algae was the highest among the algae at $19.8 \%$ for the upper and $17.5 \%$ for the lower sides. The sum of probabilities of transition showed that both sides have the same approximate probability of permanence (upper side: $39.5 \%$; lower side: $40.8 \%$ ).

\section{Discussion}

A successional complementary approach is suggested, which highlights species replacement patterns. The collected data on fouling community showed that it is possible to use Markov chain models as a tool for comparative community analysis. The fouling community on Cabo Frio Island was used as an analytical tool to evaluate the possibility of inferring probabilistic rules (disturbance, colonization, persistence and replacement) under different light effects as well as forecast successional paths. According to Irving and Connell (2002), the abundance of sessile invertebrate on bottom-facing surfaces is a good indicator of low light intensity. However, this may not always be the main cause of such patterns; the build-up of sediments can be detrimental to the survival of various organisms, preventing or reducing larval settlement and favouring organisms that have already become established. The possible influence of sediment was disregarded in our study because of the low local sedimentation rates (Mahiques et al. 2005), relatively shallow depth, and active circulation, all of which acted to prevent the accumulation of sediment on the experimental panels.

The transition matrices were capable to distinguish successional processes, which is the best method according to Gotelli (2009). The total number of 60 matrices with 6000 points on the upper side and 6000 on the lower side of the panels represented the local fouling community with their main functional groups (see at the same area Ferreira et al. 2001, Guimaraens et al. 2005, Ank et al. 2009, De Messano et al. 2009) and the successional processes.

The highest gain of functional groups was observed in the first half of the study period along the successional path, and this result reflects a rather dynamic replacement at this stage. However, the downward trend in turnover values indicated that the loss of functional groups exceeded the relative gain regardless of the panel side. Giordano (2001) suggested that disturbing agents may cause a reduction in the exchange of species in the fouling community at Santos, southeastern Brazil. In the present study, the sharp decline of functional groups mainly in the third month may have been related to local seasonal upwelling from September to November 2010 because the greatest number of resurgence events occurred at this time of year, with a significant decrease in temperature values (up to $13.5^{\circ} \mathrm{C}$, Masi 2012).

The complexity of species replacement possibilities changed along the community successional trajectory. The decreasing complexity in the set of replacements of functional groups mainly in the final study months suggests that the community had begun to show a less complex web of transitions than at the start of succession. According to Giordano (2001), a simplification in the set of transitions may represent a process of linearization or hierarchization of species/ functional groups related to their competitive abilities. The predominant groups at the end of the study period were articulate calcareous algae, sponges and encrusting bryozoans; according to Figueiredo et al. (2004), these species reflect more stable benthic communities typical of late succession, which is consistent with our results. Sponges and the encrusting bryozoan Schizoporella errata are commonly reported in advanced stages of succession and are considered excellent interference competitors because of their ability to exclude other species (Sutherland 1978, Krohling et al. 2006).

The matrices confirm the four types of species transition possibilities in both panel sides: from bare space to any functional group (colonization); from a functional group to a bare space (disturbance); from one specific group to another group (replacement); and from one group to the same group (persistence). The probability of colonization of the empty space on both sides of the panels was similar (lower: 14.1\%; upper: $18.3 \%$ ), although the transition matrices showed differences in the successional process of encrusting assemblages, in face of preferential transitions for certain functional groups in the community. The transition probability considering the successional process of colonization showed that bare space was mainly colonized by biofilm 1 and filamentous algae, although the probability of colonization of these groups differed according to the direction of the substrate, which caused a negative effect of light reduction on algae (Glasby 1999). Larger and erect algae, including articulate calcareous algae, which were exclusively observed on the upper side with higher light intensity, show longer life spans and slower growth compared with the filamentous forms and microalgae, and these last characteristics represent an opportunistic strategy usually of early stages of succession and disturbed environments (Steneck and Dethier 1994).

The transition probability indicating disturbance was greater for filamentous algae on the upper and lower faces of the panels. In the same studied area, Ferreira et al. (1998, $2001,2004)$ concluded that the greater probability of disturbance of filamentous algae on Cabo Frio Island is due to fish herbivory, which might have resulted in a probability of disturbance approximately twice that of the upper side of the panels. The herbivorous fish Stephanolepis hispidus (Actinopterygii, Monacanthidae) was commonly observed cleaning the panels (personal observation) that was re-colonized by filamentous algae, thus initiating a continuous successional process. Ceccarelli et al. (2011) recorded a drastic impact of herbivores on algal succession on a coastal coral reef in Australia, with their predation delaying the develop- 
ment of the community dominated by palatable filamentous algae of the genus Polysiphonia.

The replacement transition from a specific group to another showed the highest probabilities by the main functional groups as filamentous algae, Hydrozoa, Cirripedia and Biofilm, which indicates their common preferential transition.

The probability of persistence did not differ between the panel sides. The increase in mean persistence reflects the permanence of recruited organisms in the community, which does not indicate longevity but rather the consistency of organism settlement (Giordano 2001). On both sides, the persistence of filamentous algae was greatest, which most likely resulted from their greater ability to compete for space compared to filter-feeding benthic organisms (Coma et al. 2000).

According to Hill et al. (2004), changes in the probability of colonization and disturbance have much smaller effects on diversity than persistence. Cirripedia and Hydrozoa on the upper and lower side, respectively, showed higher persistence than the other functional groups. These barnacles are solitary organisms that attach to the substrate following settlement and metamorphosis, and they are able to alternate between active feeding and passive feeding by moving their cirrus and maintaining the cirrus outstretched (Geierman and Emlet 2009). Therefore, the greater probability of persistence on the upper side might result from the easy access to plankton, which is necessary for feeding and directly related to their survival. Many environmental parameters affect the presence of Hydrozoa in marine environments, especially luminosity and sedimentation (reviewed by Grohmann 2009). On the panels by Masi (2012), such variables were significantly smaller on the lower side. The greater probability of persistence of Hydrozoa may also be related to these smaller rates of sedimentation, which are detrimental to sessile filterfeeding organisms.

The fouling assemblages at the end of the study period were characterized as the most stable because they showed greater persistence of articulate calcareous algae on the upper side of the panels and encrusting bryozoans on the lower side. Dominant species with long life cycles and slow growth, including those that characterize these functional groups, are typical of late succession and indicate environments with high productivity and low levels of disturbance (reviewed by Figueiredo et al. 2004). The encrusting bryozoans also show improved competitive abilities compared with the other sessile organisms, and they not only occupied the available space but also grew in other species (Sutherland and Karlson 1977, Sutherland 1978, Xavier et al. 2008). Colonial organisms may overgrow, which gives them an advantage in the occupation of space compared to solitary organisms.

Assessments of the assemblage processes exhibited by each functional group indicate the relationship between ecological succession models and the fouling community dynamics on Cabo Frio Island. The difference in probabilities of transition shown through the matrices suggests a preference of specific functional groups for the upper and/or lower sides of the panels that is related to the successional processes (colonization, replacement, disturbance and persistence).
According to the succession model proposed by Connell and Slatyer (1977), the species settlement at later succession stages may be facilitated by earlier organisms. Preferential transition in the replacement of functional groups indicates a process of facilitation regardless of the panel direction. The filamentous algae played a facilitator role on the upper side, whereas the biofilms formed by microorganisms, including bacteria and diatoms, served as an attractive substrate for the settlement of benthic organisms on the lower side. Besides, inhibitory processes (Connell and Slatyer 1977) also occurred as indicated by the smaller probability of transition from one functional group to another, eg. filamentous algae and Cirripedia on the upper side and filamentous algae and Hydrozoa on the lower side. The mechanism of tolerance (Connell and Slatyer 1977) would have been evident if the probability of transition between functional groups were similar, which did not occur in the present study.

The formation of patches representing multiple stable points (Sutherland 1978) indicated a mosaic patterned distribution that is common in the sublittoral habitats of natural substrate (Menge et al. 2005) and fouling communities (Sutherland and Karlson 1977, Masi 2012). The changes in transition matrices of both panel sides recorded at the time scale (12 months) showed that the fouling community succession is not a sequence of independent states with a simple equilibrium state, but several cascading events related to different transition probabilities, which may change at each time step.

In summary, the succession paths evaluated using the global transition matrices changed at each time step because they are dependent on the renewal rate of organisms; therefore, they are informative of the changing processes in the community. Species that have similar functions are replaced through competition and herbivory, thus promoting distinctions between earlier and late functional groups. The rate of the successional process measured by transition matrices and complexity analysis, based on probabilistic rates related to the successional community processes may be used to predict future situations, and thus accept the hypothesis tested. Although transition probability matrices for species and guilds can be used to improve analyses of successional processes, more original data with the same methodology will corroborate and support the functional model analysis. As generalized by Margalef (1991), the transition probability matrices of the fouling community on Cabo Frio Island show deterministic components and stochastic elements that render them self-organizable community.

Acknowledgements. This work was supported by the Brazilian Agency for Research Development - CNPq/ FAPERJ/PRONEX under Grant E-26/111.438/2010. We are grateful to the Biofouling Laboratory (IEAPM) team for field assistance.

\section{References}

Ank, G., T.F. Porto, R.C. Pereira and B.A.P. da Gama. 2009. Effects of different biotic substrata on mussel attachment. Biofouling 25: $173-180$. 
Breitburg, D.L. 1985. Development of a subtidal epibenthic community: factors affecting species composition and the mechanisms of succession. Oecologia 65: 173-184.

Caswell, H. 2001. Matrix Population Models: Construction, Analysis and Interpretation. 2nd edition. Sinauer Associates, Massachusetts.

Ceccarelli, D.M. G.P. Jones and L.J. McCook. 2011. Interactions between herbivorous fish guilds and their influence on algal succession on a coastal coral reef. J. Exp. Mar. Biol. Ecol. 399: 60-67.

Clements F.E. 1916. Plant Succession: An Analysis of the Development of Vegetation. Carnegie Institution of Washington, Washington.

Coma, R., M. Ribes, J. Gili and M. Zabala. 2000. Seasonality in coastal benthic ecosystems. Trends Ecol. Evol. 15: 448-453.

Connell J.H. and R.O. Slatyer. 1977. Mechanisms of succession in natural communities and their role in community stability and organization. Am. Nat. 111: 1119-1144.

Dean T.A. and L.E. Hurd. 1980. Development in an estuarine fouling community: the influence of early colonists on later arrivals. Oecologia 46: 295-301.

De Messano L.V.R., L. Sathler, L.Y. Reznik and R. Coutinho. 2009. The effect of biofouling on localized corrosion of the stainless steels N08904 and UNS S32760. Int. Biodeter. Biodegr. 63: 607-614.

Ferreira D.E.L., A.C. Peret and R. Coutinho. 1998. Seasonal grazing rates and food processing by tropical fish. J. Fish Biol. 53: $222-235$.

Ferreira C.E.L., J.E.A. Gonçalves and R. Coutinho. 2001. Community structure of fishes and habitat complexity in a tropical rocky shore. Environ. Biol. Fish 61: 353-369.

Ferreira C.E.L., S.R. Floeter, J.L. Gasparini, B.P. Ferreira and J.C. Joyeux. 2004. Trophic structure patterns of Brazilian reef fishes: a latitudinal comparison. J. Biogeogr. 31: 1093-1106.

Figueiredo M.A.O., M.B.B. Barreto and R.P. Reis. 2004. Caracterização das macroalgas nas comunidades marinhas da Área de Proteção Ambiental de Cairuçú, Parati, RJ - subsídios para futuros monitoramentos. Rev. Bras. Bot. 27: 11-17.

Geierman C. and R. Emlet. 2009. Feeding behavior, cirral fan anatomy, Reynolds numbers, and leakiness of Balanus glandula, from post-metamorphic juvenile to the adult. J. Exp. Mar. Biol. Ecol. 379: $68-76$.

Giordano F. 2001. Colonização de placas de fouling no estuário de Santos (Santos-SP): análise transicional e de sensibilidade complementando a abordagem baseada em recobrimentos específicos e diversidade. PhD Thesis, University of São Paulo, São Paulo, Brazil.

Glasby T.M. 1999. Effects of shading on subtidal epibiotic assemblages. J. Exp. Mar. Biol. Ecol. 234: 275-290.

Glasby T.M. 2000. Surface composition and orientation interact to affect subtidal epibiota. J. Exp. Mar. Biol. Ecol. 248: 177-190.

Gotelli N.J. 2009. A Primer of Ecology. 4th edition. Sinauer Associates, Massachussets.

Greene, C.H., A. Schoener and E. Corets. 1983. Succession on marine hard substrata: the adaptive significance of solitary and colonial strategies in temperate fouling communities. Mar. Ecol. Prog. Ser. 13: 121-129

Grohmann P.A. 2009. Hydroids (Cnidaria, Hydrozoa) of the intertidal zone of Governador and Paquetá Islands, Guanabara Bay, Rio de Janeiro, Brazil. Iheringia (Zoology) 99: 291-294.

Guimaraens, M.A., A.M. Paiva and R. Coutinho. 2005. Modeling Ulva spp. dynamics in a tropical upwelling region. Ecol. Model. 188: 448-460.
Hill, M.F., J.D. Witman and H. Caswell. 2004. Markov chain analysis of succession in a rocky subtidal community. Am. Nat. 164: 46-61.

Irving, A.D., and S.D. Connell . 2002. Sedimentation and light penetration interact to maintain heterogeneity of subtidal habitats: algal versus invertebrate dominated assemblages. Mar. Ecol. Prog. Ser. 245: 8-91.

ITIS (Integrated Taxonomic Information System). 2009. (available from: http://www.itis.usda.gov).

Kohler K. and S. Gill. 2006. Coral Point Count with Excel extensions (CPCe): A Visual Basic program for the determination of coral and substrate coverage using random point count methodology. Comput. Geosci. 32: 1259-1269.

Krohling W., D.S. Brotto and I.R. Zalmon. 2006. Functional role of fouling community on an artificial reef at the northern coast of Rio de Janeiro state, Braz. J. Oceanogr. 54: 183-191.

López M.S. and R. Coutinho. 2008. Acoplamento Plâncton-Bentos: o papel do suprimento larval na estrutura das comunidades bentônicas de costões rochosos. Oecologia Brasil. 12: 575-601.

Mahiques M.M., M.C. Bícego, I.C.A. Silveira, S.H.M. Sousa, R.A. Lourenço and M.M. Fukumoto. 2005. Modern sedimentation in the Cabo Frio upwelling system, Southeastern Brazilian shelf. An. Acad. Bras. Ciênc. 77: 535-548.

Margalef, R. 1991. Teoría de los Sistemas Ecológicos. Universidad de Barcelona Editora, Barcelona.

Masi B.P. 2012. A influência de características oceanográficas na trajetória sucessional das incrustações biológicas na região de ressurgência de Cabo Frio, Rio de Janeiro. PhD Thesis, Ecology, University of North Rio de Janeiro State, Campos dos Goytacazes, Brazil.

Maughan B.C. 2001. The effects of sedimentation and light on recruitment and development of a temperate, subtidal, epifaunal community. J. Exp. Mar. Biol. Ecol. 256: 59-71.

Menge, B.A., G.W. Allisonb, C.A. Blanchettec, T.M. Farrelld, A.M. Olsona, T.A. Turnere and P.V. Tamelenf. 2005. Stasis or kinesis? Hidden dynamics of a rocky intertidal macrophyte mosaic revealed by a spatially explicit approach. J. Exp. Mar. Biol. Ecol. 314: 3-39.

Pawlowski, C. and C.A. McCord. 2009. Markov model for assessing ecological stability successional processes. Ecol. Model. 220: 86-95.

Platt W.J. and J.H. Connell. 2003. Natural disturbances and directional replacement of species. Ecol. Monogr. 73: 507-522.

Prach K. and L.R. Walker. 2011. Four opportunities for studies of ecological succession. Trends Ecol. Evol. 26: 119-123.

Phillips J.C., G.A. Kendrick and P.S. Lavery. 1997. A test of a functional group approach to detecting shifts in macrolgal communities along a disturbance gradient. Mar. Ecol. Prog. Ser. 153: $125-138$.

Sauer-Machado K.R.S. 2006. Estudo sucessional das incrustações biológicas em painéis artificiais na Ilha de Porto Belo (Porto Belo, SC), através da análise de matrizes de probabilidade de transição e análise de sensibilidade. $\mathrm{PhD}$ Thesis, Federal University of Rio de Janeiro, Brazil.

Sebens K. 1986. Spatial relationships among encrusting marine organisms in the New England subtidal zone. Ecol. Monogr. 56: 73-96.

Steneck, R.S. and M.N. Dethier. 1994. A functional group approach to the structure of algal-dominated communities. Oikos 69: 476-498. 
Sutherland J.P. 1978. Functional roles of Schizoporella and Styela in the fouling community at Beaufort, North Carolina. Ecology 59: $257-264$

Sutherland J.P. and R.H. Karlson. 1977. Development and stability of the fouling community at Beaufort, North Carolina. Ecol. Monogr. 47: 425-446.

Svane I.B. and C.M. Young. 1989. The ecology and behavior of ascidian larvae. Oceanogr. Mar. Biol. An. Rev. 27: 45-90

Tanner J.E., T.P. Hughes and J.H. Connell. 1994. Community-leve density dependence: an example from a shallow coral assemblage. Ecology 90: 506-516.

Underwood A.J. 1999. History and recruitment in structure of intertidal assemblages on rocky shores: an introduction to problems for interpretation of natural change. In: M. Whitfield, J. Matthews and C. Reynolds (eds.), Aquatic Life Cycle Strategies: Survival in a Variable Environment. Marine Biological Association of the United Kingdom, Plymouth. pp. 79-96.
Usher M.B. 1979. Markovian approaches to ecological succession. J. Anim. Ecol. 48: 413-426.

Valentin J. 1987. Spatial structure of the zooplankton community in the Cabo Frio region (Brazil) influenced by coastal upwelling. Hydrobiologia 113: 183-199.

Wootton J.T. 2001. Prediction in complex communities: analysis of empirically derived Markov models. Ecology 82: 580-598.

Xavier E.D.A., B.A.P. da Gama, T.F. Porto, B.L. Antunes and R.C. Pereira. 2008. Effects of disturbance area on fouling communities from a tropical environment: Guanabara Bay, Rio de Janeiro, Brazil. Braz. J. Oceanogr. 56: 73-84.

Received February 16, 2016 Revised July 7, 2016 Accepted August 23, 2016 